\title{
DOI https://doi.org/10.30525/978-9934-26-112-1-2
}

\section{TEST TO DETERMINE THE LEVEL OF PSYCHOLOGICAL READINESS OF ATHLETES IN SHOOTING TO OVERCOME COMPETITIVE DIFFICULTIES}

\author{
Dmitriieva N. S. \\ Master's student \\ National Pedagogical Dragomanov University \\ Kyiv, Ukraine
}

The test is designed to determine the level of psychological readiness of athletes in shooting to overcome competitive difficulties.

The test to determine the level of psychological readiness of athletes in shooting to overcome competitive difficulties was developed by the author on the basis of his own observations and research $[1 ; 2 ; 3]$. The test contains 20 questions, in each of them the respondent is offered three possible answers (table 1).

Таблиця 1

Test to determine the level of psychological readiness of athletes in shooting to overcome competitive difficulties

Dmitriieva Nikol Subkhanivna

\begin{tabular}{|c|c|}
\hline Ukrainian language & English \\
\hline $\begin{array}{l}\text { 1. Наскільки легко і вільно ви } \\
\text { рухаєтеся? } \\
\text { А. Більше, ніж зазвичай } \\
\text { Б. Як завжди } \\
\text { В. Менше, ніж зазвичай } \\
\text { 2. Як ви оцінюєте свій настрій? } \\
\text { А. Краще, ніж зазвичай } \\
\text { Б. Як завжди } \\
\text { В. Гірше, ніж зазвичай } \\
\text { 3. Як ви уявляєте план своїх } \\
\text { тактичних дій на майбутніх } \\
\text { змаганнях? ва зазвичай } \\
\text { А. Краще, ніж зан } \\
\text { Б. Як завжди } \\
\text { В. Гірше, ніж зазвичай } \\
\text { 4. Наскільки легко і вільно ви } \\
\text { дихаєте? }\end{array}$ & $\begin{array}{l}\text { 1. How easily and freely do you } \\
\text { move? } \\
\text { A. More than usual } \\
\text { B. As always } \\
\text { C. Less than usual } \\
\text { 2. How do you assess your mood? } \\
\text { A. Better than usual } \\
\text { B. As always } \\
\text { C. Worse than usual } \\
\text { 3. How do you imagine your } \\
\text { tactical action plan for future } \\
\text { competitions? } \\
\text { A. Better than usual } \\
\text { B. As always } \\
\text { C. Worse than usual } \\
\text { 4. How easily and freely do you } \\
\text { breathe? }\end{array}$ \\
\hline
\end{tabular}




\begin{tabular}{|c|c|}
\hline $\begin{array}{l}\text { А. Краще, ніж зазвичай } \\
\text { Б. Як завжди } \\
\text { В. Гірше, ніж зазвичай } \\
\text { 5. Як ви оцінюєте свій емоційний } \\
\text { стан? } \\
\text { А. Краще, ніж зазвичай } \\
\text { Б. Як завжди } \\
\text { В. Гірше, ніж зазвичай } \\
\text { 6. Наскільки вас турбують думки } \\
\text { про те, яким буде ваш підсумок } \\
\text { змагань? } \\
\text { А. Більше, ніж зазвичай } \\
\text { Б. Як завжди } \\
\text { В. Менше, ніж зазвичай } \\
\text { 7. Як ви оцінюєте стабільність } \\
\text { своєї спортивної техніки? } \\
\text { А. Вище, ніж зазвичай } \\
\text { Б. Як завжди } \\
\text { В. Нижче, ніж зазвичай } \\
\text { 8. Чи турбують вас думки про } \\
\text { ваш виступ у змаганнях? } \\
\text { А. Більше, ніж зазвичай } \\
\text { Б. Як завжди } \\
\text { В. Менше, ніж зазвичай } \\
\text { 9. Як ви оцінюєте відчуття } \\
\text { рівноваги в своїх рухах? } \\
\text { А. Краще, ніж зазвичай } \\
\text { Б. Як завжди } \\
\text { В. Гірше, ніж зазвичай } \\
\text { 10. } \\
\text { взаємовідносинами } \\
\text { тренером? } \\
\text { А. Більше, ніж зазвичай } \\
\text { Б. Як завжди } \\
\text { В. Менше, ніж зазвичай } \\
\text { 11. Як ви оцінюєте свої шанси на } \\
\text { успіх в майбутніх змаганнях? } \\
\text { А. Вище, ніж зазвичай } \\
\text { Б. Як завжди } \\
\text { В. Нижче, ніж зазвичай } \\
\text { 12. Як ви відчуваєте роботу свого } \\
\text { серця? } \\
\text { А. Краще, ніж зазвичай } \\
\text { Б. Як завжди } \\
\text { В. Гірше, ніж зазвичай }\end{array}$ & $\begin{array}{l}\text { A. Better than usual } \\
\text { B. As always } \\
\text { C. Worse than usual } \\
\text { 5. How do you assess your } \\
\text { emotional state? } \\
\text { A. Better than usual } \\
\text { B. As always } \\
\text { C. Worse than usual } \\
\text { 6. How worried are you about what } \\
\text { your competition will be like? } \\
\text { A. More than usual } \\
\text { B. As always } \\
\text { C. Less than usual } \\
\text { 7. How do you assess the stability } \\
\text { of your sports equipment? } \\
\text { A. Higher than usual } \\
\text { B. As always } \\
\text { C. Lower than usual } \\
\text { 8. Are you worried about your } \\
\text { performance in competitions? } \\
\text { A. More than usual } \\
\text { B. As always } \\
\text { C. Less than usual } \\
\text { 9. How do you assess the sense of } \\
\text { balance in your movements? } \\
\text { A. Better than usual } \\
\text { B. As always } \\
\text { C. Worse than usual } \\
\text { 10. Are you satisfied with the } \\
\text { relationship with your coach? } \\
\text { A. More than usual } \\
\text { B. As always } \\
\text { C. Less than usual } \\
\text { A. Better than usual } \\
\text { B. As always } \\
\text { C. Worse than usual } \\
\text { 13. To what extent are you able to } \\
\text { chances of success in } \\
\text { competitions? } \\
\text { A. Higher than usual } \\
\text { B. As always } \\
\text { C. Lower than usual } \\
\text { 12. How do you feel the work of } \\
\text { yourt? }\end{array}$ \\
\hline
\end{tabular}




\begin{tabular}{|c|c|}
\hline 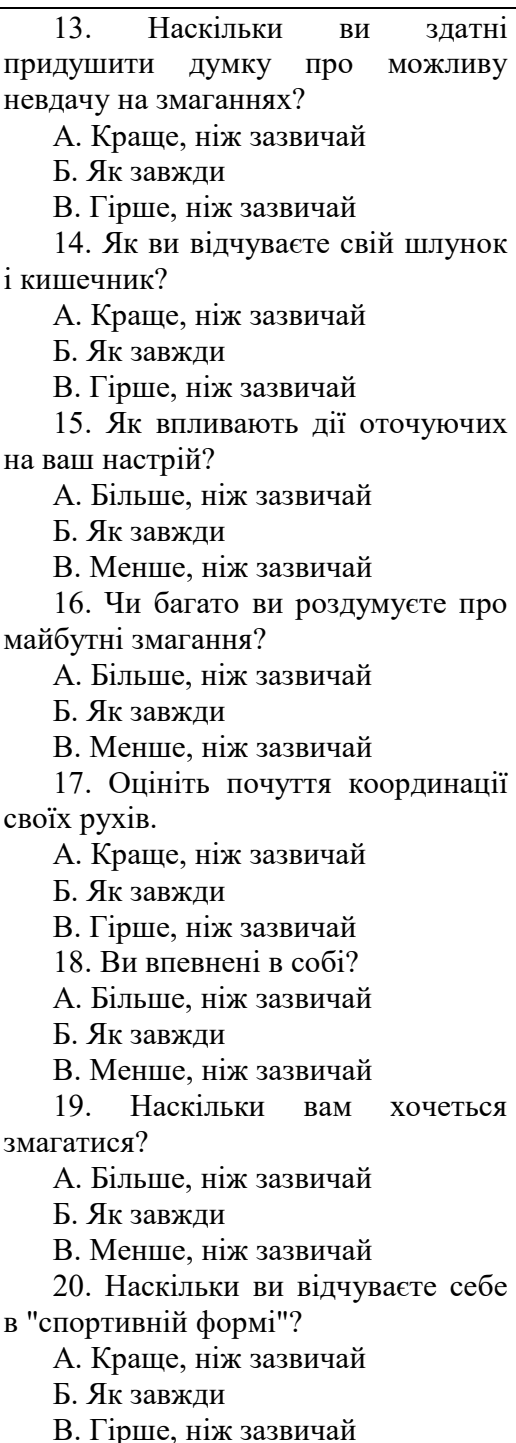 & $\begin{array}{l}\text { suppress the idea of possible failure in } \\
\text { competitions? } \\
\text { A. Better than usual } \\
\text { B. As always } \\
\text { C. Worse than usual } \\
\text { 14. How do you feel your stomach } \\
\text { and intestines? } \\
\text { A. Better than usual } \\
\text { B. As always } \\
\text { C. Worse than usual } \\
\text { 15. How do the actions of others } \\
\text { affect your mood? } \\
\text { A. More than usual } \\
\text { B. As always } \\
\text { C. Less than usual } \\
\text { 16. Do you think a lot about future } \\
\text { competitions? } \\
\text { A. More than usual } \\
\text { B. As always } \\
\text { C. Less than usual } \\
\text { 17. Evaluate the sense of } \\
\text { coordination of their movements. } \\
\text { A. Better than usual } \\
\text { B. As always } \\
\text { C. Worse than usual } \\
\text { 18. Are you confident? } \\
\text { A. More than usual } \\
\text { B. As always } \\
\text { C. Less than usual } \\
\text { 19. How much do you want to } \\
\text { compete? } \\
\text { A. More than usual } \\
\text { B. As always } \\
\text { C. Less than usual } \\
\text { 20. How do you feel in "sports } \\
\text { form"? } \\
\text { A. Better than usual } \\
\text { B. As always } \\
\text { C. Worse than usual }\end{array}$ \\
\hline
\end{tabular}

Option "A" is evaluated in 3 points, option "B" - 2 points, option "C" - one point.

The level of psychological readiness of athletes in shooting to overcome competitive difficulties is determined as follows: $41-60$ points indicate 
psychological readiness at the level of practical experience; $21-40$ points indicate psychological readiness at the level of theoretical experience; $0-20$ points indicate psychological readiness at the level of motivation.

\title{
References:
}

1. Dmitriieva, N. Psychological training of future specialists in physical culture and sports for the activities of a sports coach in higher education institutions. Engineering and Educational Technologies. 2021. № 9 (1). P. 90-101. DOI: https://doi.org/10.30929/2307-9770.2021.09.01.08

2. Dmitriieva, N. S. Methodological approaches to the formation of psychological readiness of athletes in shooting to overcome competitive difficulties. SWorldJournal. 2020. № 6 (05). P. 40-43. DOI: $10.30888 / 2663-5712.2020-06-05-033$

3. Дмітрієва Н. С. Методика формування психологічної готовності спортсменів із кульової стрільби до подолання змагальних труднощів. Вісник Запорізького національного університету: Збірник наукових пращъ. Фізичне виховання та спорт. 2020. № 2. С. 120-125. DOI: $10.26661 / 2663-5925-2020-2-18$

\section{DOI https://doi.org/10.30525/978-9934-26-112-1-3}

\section{МОДЕЛЬНІ ХАРАКТЕРИСТИКИ ТЕХНІКО-ТАКТИЧНОЇ ПІДГОТОВЛЕНОСТІ КВАЛІФІКОВАНИХ ЗАХИСНИКІВ ЧЕМПІОНАТУ УКРАЇНИ 3 ФУТБОЛУ}

\author{
Карпа I. Я. \\ кандидат наук з фізичного виховання та спорту, дочент, \\ Львівський державний університет фізичної культури \\ імені Івана Боберського \\ Колобич О. В. \\ старший викладач кафедри футболу \\ Львівський державний університет фізичної культури \\ імені Івана Боберського \\ м. Львів, Україна
}

Футбол є одним з найбільш популярних та розвинених видів спорту в світі. Змагальна діяльність у футболі характеризується високим рівнем конкуренції між провідними клубними та національними 